\title{
The Effect of Lateral Connection in Moment Carrying Capacity of Frame in RC High Rise Structure using Pushover Analysis
}

\author{
Rohit Ravindra Mahorkar \\ P.G. Student, \\ Department of Civil Engineering, MGM's JNEC, \\ Aurangabad-431002, Maharashtra, India.
}

\author{
L.G. Kalurkar \\ Assistant Professor, \\ Department of Civil Engineering, MGM's JNEC, \\ Aurangabad-431002, Maharashtra, India.
}

\begin{abstract}
Now a days in Reinforced Concrete "Specific Moment Resisting Frames" are used as a part of seismic force resisting methods in buildings which are created to resist earthquakes. Beam-column joints, columns, and beams in moment frames are proportioned as well as detailed to resist shearing, axial, and flexural measures which result as a construction sways via many displacement cycles in intense earthquake ground shaking. Exclusive proportioning \& detailing requirements lead to a frame capable of resisting strong earthquake shaking with no substantial loss of strength or stiffness. These moment resisting frames are called "Special Moment Resisting Frames" due to these extra needs, which help the seismic resistance in comparison with much less stringently detailed Ordinary and intermediate Moment Resisting Frames. The design criteria for SMRF buildings are provided in IS 13920 (2002). In this particular study, the buildings are intended both as OMRF and SMRF, and the performance of theirs is compared. Because of this, the structures are modelled and pushover analysis is performed in SAP2000. The pushover curves are plotted out of the analysis results and also the behaviour of structures is analyzed for different assistance conditions as well as infill conditions. The behaviour variables are additionally discovered for every construction while using values from pushover curve and it is investigated.
\end{abstract}

Keywords - Static Nonlinear analysis, SMRF, OMRF, Pushover analysis, SAP2000, plastic hinges, response reduction factor.

\section{INTRODUCTION}

Earthquake is a worldwide phenomenon. Because of regular occurrence of earthquakes it is no more considered as being an act of God quite a systematic developing that has be investigated. Throughout earthquake, ground motions happen both vertically and horizontally in arbitrary fashions that cause structures to vibrate as well as induce inertia forces in them. Analysis of destroys incurred in moment resisting $\mathrm{RC}$ framed constructions put through previous earthquake show which disappointment could be because of utilization of concrete not having sufficient resistance, soft storey, beam column joint disaster for improper anchorage or weak reinforcements, column failure causing storey mechanism. Beam-column connection is regarded as among the potentially weaker parts whenever a system is put through seismic loading. . Figures of several of the beam Column joint column and failure collapses in previous earthquakes are revealed with Fig. 1.1. Thus this kind of column as well as joint disaster needs to be provided particular attention.

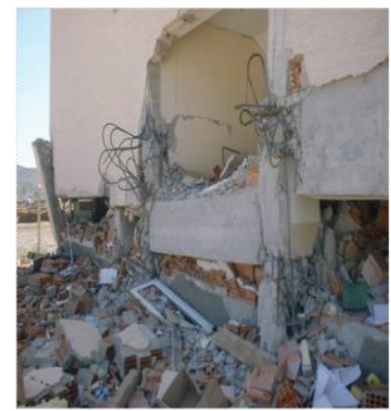

(a)

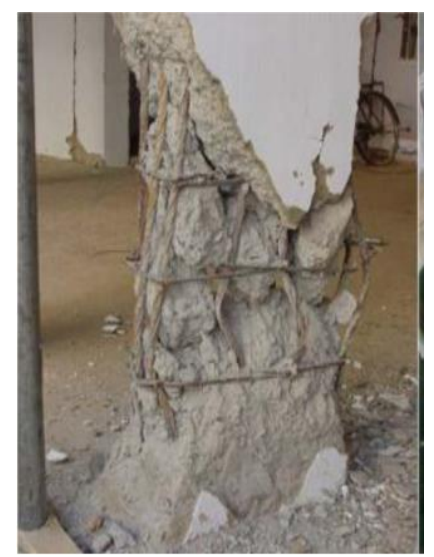

(c)

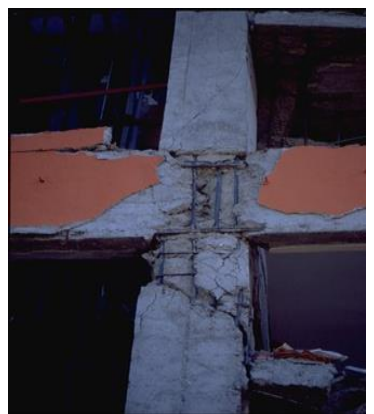

(b)

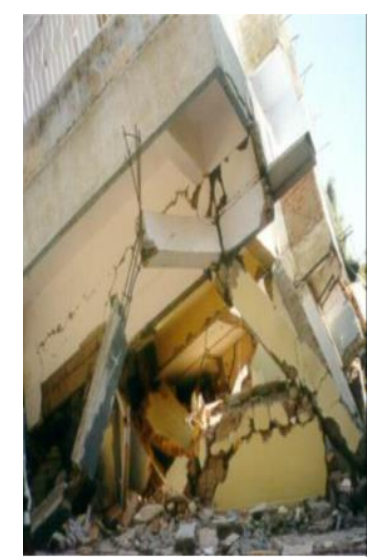

(d)
Fig 1.1 Failure of buildings due to storey mechanism in past earthquakes: (a) Failure of column with eccentric connection during Turkey earthquake, 2003 (b) failure of column and beam-column joint during Turkey earthquake, 2003 (c) and (d) Failure building due to column storey mechanism during Bhuj Earthquake, 2001.

When to use SMRF - Moment frames are usually selected as the seismic force resisting structure when architectural space planning flexibility is ideal. When concrete second frames are selected for structures given to Seismic Design Categories III, IV or perhaps V, they're expected to be thorough as unique reinforced concrete moment frames. Proportioning \& detailing demands for a unique moment frame will allow the frame to easily undergo considerable inelastic deformations which are anticipated in these seismic layout groups Both power and stiffness have to be viewed in the design of unique moment frames. Based on IS 13920(2002), specific moment frames are permitted to be designed for a force reduction factor of $\mathrm{R}=5$. That's, they're 
allowed to be made for a base shear equal to one fifth of the worth obtained from an elastic effect evaluation. Moment frames are versatile lateral systems; thus, strength needs might be managed by the minimum base shear equations of the code.

\section{PROBLEM STATEMENT}

Present study focus on different aspects associated with the functionality of SMRF buildings. The primary goal of current study will be the analysis of relative functionality of OMRF and SMRF frames, designed as per IS Codes, utilizing nonlinear analysis. The greater realistic performance of the SMRF and OMRF building necessitates modelling the stiffness along with strength of the infill walls. The variations in the kind of the infill walls utilizing in Indian constructions are considerable. Based on the modulus of elasticity and also the strength, it could be classified as weak or strong. The 2 extreme cases of infill walls, weak and strong are thought by modelling the stiffness as well as power of infill wall space as accurately as you possibly can in the current study. The behaviour of structures depends on the kind of soils. Determined by the foundations resting on medium soils, the displacement boundary conditions in the bottom part of foundations may be looked at as hinged or maybe fixed. As the modelling of soils isn't in the range of the research, 2 boundary conditions, fixed and hinged, which symbolize 2 extreme conditions, are considered.

\section{METHODOLOGY}

\section{Building Configurations and Design Details}

A maximum of 12 frames are selected by different amount of stories quantity of bays, infill wall configurations, and style strategy with regard to effect reduction factors as well as confinement detailing. A comprehensive explanation of all of the frames considered is provided in Table (A). The storey height is $3.5 \mathrm{~m}$ and bay width is $3 \mathrm{~m}$, that is exact same for those frames. Each and every frame was created as SMRF and OMRF considering response reduction things including 3 and 5. IS code suggests a response reduction factor of 3 for OMRF plus 5 for SMRF. The style of the frames is performed by conducting linear static analysis of bare frames as well as accounting for all of the load combinations recommended by IS 1893(2002). Two serious conditions like fixed and hinged support conditions are mirrored in the research. For convenient presentation of results, a good naming convention is followed. 4S7B-SMRF-B-F presents a bare frame, designed as SMRF with fixed support conditions. 4S7B-SMRF-I-H is an infill walled frame, designed as SMRF with hinged support conditions. A building may be treated as being a bare frame in case the infill frames are constructed with a definite gap between the wall space \& columns therefore the infill walls don't engage in lateral loads. The structure frame with infill walls offered in all of stories is viewed as a completely infill frame.

\begin{tabular}{|c|c|c|c|c|c|c|c|}
\hline $\begin{array}{l}\text { Sr } \\
\text { No }\end{array}$ & Frame Name & $\begin{array}{c}\text { Frame } \\
\text { type }\end{array}$ & $\begin{array}{l}\text { No. of } \\
\text { storey }\end{array}$ & $\begin{array}{c}\text { No. of } \\
\text { bays }\end{array}$ & $\mathbf{R}$ & Frame type & $\begin{array}{c}\text { Support } \\
\text { conditions }\end{array}$ \\
\hline 1 & $\begin{array}{l}\text { 4S7B-SMRF- } \\
\text { B-F }\end{array}$ & Bare & 4 & 7 & 5 & SMRF & $\begin{array}{c}\text { Fixed \& } \\
\text { Hinge }\end{array}$ \\
\hline 2 & $\begin{array}{l}\text { 8S7B-SMRF- } \\
\text { B-F }\end{array}$ & Bare & 8 & 7 & 5 & SMRF & $\begin{array}{c}\text { Fixed \& } \\
\text { Hinge }\end{array}$ \\
\hline 3 & $\begin{array}{l}\text { 10S7B- } \\
\text { SMRF-B-F }\end{array}$ & Bare & 10 & 7 & 5 & SMRF & $\begin{array}{c}\text { Fixed \& } \\
\text { Hinge }\end{array}$ \\
\hline 4 & $\begin{array}{l}\text { 6S2B-SMRF- } \\
\text { B-F }\end{array}$ & Bare & 6 & 2 & 5 & SMRF & $\begin{array}{c}\text { Fixed \& } \\
\text { Hinge }\end{array}$ \\
\hline 5 & $\begin{array}{l}\text { 6S4B-SMRF- } \\
\text { B-F }\end{array}$ & Bare & 6 & 4 & 5 & SMRF & $\begin{array}{c}\text { Fixed \& } \\
\text { Hinge }\end{array}$ \\
\hline 6 & $\begin{array}{l}\text { 6S6B-SMRF- } \\
\text { B-F }\end{array}$ & Bare & 6 & 6 & 5 & SMRF & $\begin{array}{c}\text { Fixed \& } \\
\text { Hinge }\end{array}$ \\
\hline 7 & $\begin{array}{l}\text { 4S7B-OMRF- } \\
\text { B-F }\end{array}$ & Bare & 4 & 7 & 3 & OMRF & $\begin{array}{c}\text { Fixed \& } \\
\text { Hinge }\end{array}$ \\
\hline 8 & $\begin{array}{l}\text { 8S7B-OMRF- } \\
\text { B-F }\end{array}$ & Bare & 8 & 7 & 3 & OMRF & $\begin{array}{c}\text { Fixed \& } \\
\text { Hinge }\end{array}$ \\
\hline 9 & $\begin{array}{l}\text { 10S7B- } \\
\text { OMRF-B-F }\end{array}$ & Bare & 10 & 7 & 3 & OMRF & $\begin{array}{c}\text { Fixed \& } \\
\text { Hinge }\end{array}$ \\
\hline 10 & $\begin{array}{l}\text { 6S2B-OMRF- } \\
\text { B-F }\end{array}$ & Bare & 6 & 2 & 3 & OMRF & $\begin{array}{c}\text { Fixed \& } \\
\text { Hinge }\end{array}$ \\
\hline 11 & $\begin{array}{l}\text { 6S4B-OMRF- } \\
\text { B-F }\end{array}$ & Bare & 6 & 4 & 3 & OMRF & $\begin{array}{c}\text { Fixed \& } \\
\text { Hinge }\end{array}$ \\
\hline 12 & $\begin{array}{l}\text { 6S6B-OMRF- } \\
\text { B-F }\end{array}$ & Bare & 6 & 6 & 3 & OMRF & $\begin{array}{c}\text { Fixed \& } \\
\text { Hinge }\end{array}$ \\
\hline
\end{tabular}

Table (A) Details of all the frames

Material properties and Geometric parameters assumed

\begin{tabular}{|l|l|c|}
\hline $\begin{array}{l}\text { Sr } \\
\text { No. }\end{array}$ & Design Parameter & Value \\
\hline 1 & Unit weight of concrete & $25 \mathrm{KN} / \mathrm{m}^{3}$ \\
\hline 2 & Unit weight of Infill walls & $18 \mathrm{KN} / \mathrm{m}^{3}$ \\
\hline 3 & Characteristic Strength of concrete & $25 \mathrm{MPa}$ \\
\hline 4 & Characteristic Strength of concrete & $415 \mathrm{MPa}$ \\
\hline 5 & $\begin{array}{l}\text { Compressive strength of strong } \\
\text { masonry }\left(E_{m}\right)\end{array}$ & $5000 \mathrm{MPa}$ \\
\hline 6 & $\begin{array}{l}\text { Compressive strength of weak } \\
\text { masonry }\left(E_{m}\right)\end{array}$ & $350 \mathrm{MPa}$ \\
\hline 7 & Damping ratio & $5 \%$ \\
\hline 8 & Modulus of elasticity of steel & $2 \mathrm{e} 5 \mathrm{MPa}$ \\
\hline 9 & Slab thickness & $150 \mathrm{~mm}$ \\
\hline 10 & Wall thickness & $230 \mathrm{~mm}$ \\
\hline 11 & Beam & $300 \mathrm{~mm} \times 300 \mathrm{~mm}$ \\
\hline 12 & Column & \\
\hline
\end{tabular}

Seismic Design Data assumed for Special and Ordinary Moment Resisting Frames

\begin{tabular}{|l|l|c|}
\hline $\begin{array}{l}\text { Sr } \\
\text { No. }\end{array}$ & Design Parameter & Value \\
\hline 1 & Seismic Zone & V \\
\hline 2 & Zone factor (Z) & 0.36 \\
\hline 3 & Response reduction factor (R) & 5 \\
\hline 4 & Response reduction factor (R) & 3 \\
\hline 5 & Importance factor (I) & 1 \\
\hline 6 & Soil type & Medium soil \\
\hline 7 & Damping ratio & $5 \%$ \\
\hline
\end{tabular}

\section{Pushover Analysis}

Performance examination of the designed frames is performed using nonlinear static pushover analysis. The modelling of the created frames for nonlinear examination is 
performed inside the Program SAP2000 Nonlinear. Pushover examination is a fixed, nonlinear procedure to analysis a construction where loading is incrementally enhanced by using a particular predefined pattern (i.e., inverted triangular or maybe uniform). Local nonlinear effects are modelled and the system is pushed until a collapse mechanism is created. With the increased the magnitude of a lot, weak back links and failure modes of the structure are located. At every step, system is pushed until sufficient hinges form to get a curve between base shear of the structure and their corresponding this curve and roof displacement widely known as pushover curve. At every phase, the entire base shear as well as the best displacement are plotted to have this particular pushover curve at different phases. It provides a concept of the maximum base shear which the system is effective at resisting and also the corresponding inelastic drift. For frequent buildings, it also provides an estimation of the global strength and stiffness in terminology of displacement and force of the structure. A common design frame $\&$ a regular pushover curve diagram is shown in fig below -

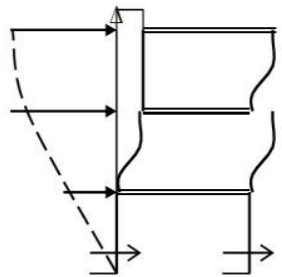

Base Shear (V)

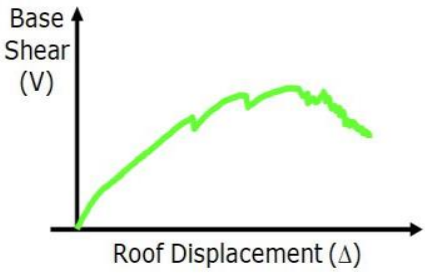

Roof Displacement $(\Delta)$
Typical Pushover Curve

\section{Modelling Of Structural Elements}

Beams and columns have been modelled as frame components readily available in SAP 2000, with the central lines joined at nodes. Beam column joints are viewed as rigid beam-column joints and these're modelled giving end offsets in the joints. A rigid zone factor of 1.0 is assumed to replicate the rigidity at the joints. The floor slabs are assumed acting as diaphragms, and that ensure important activity of the entire vertical lateral load resisting elements. The weight of the slab was sent out as trapezoidal and triangular ton on the surrounding beams as per IS 456:2000.

\section{RESULT}

\section{A. COMPARISON OF SMRF AND OMRF: BARE FRAME FIXED SUPPORT}

In this specific comparison, the functionality of ordinary moment resisting special moment and frames resisting frames with fixed support circumstances are deemed. The base shear compared to roof displacement at every analysis step is obtained. The pushover curves are provided in every case. Figure 4.1 shows pushover curves of 4S7B bare frames designed as both SMRF and OMRF, with fixed support conditions. In Fig 4.1, the starting shear capacity of 4S7B OMRF is approximately $40 \%$ much more than that of a 4S7B SMRF building. But the displacement capacity of 4S7B SMRF is approximately 3.5 times than that of a 4S7B OMRF.

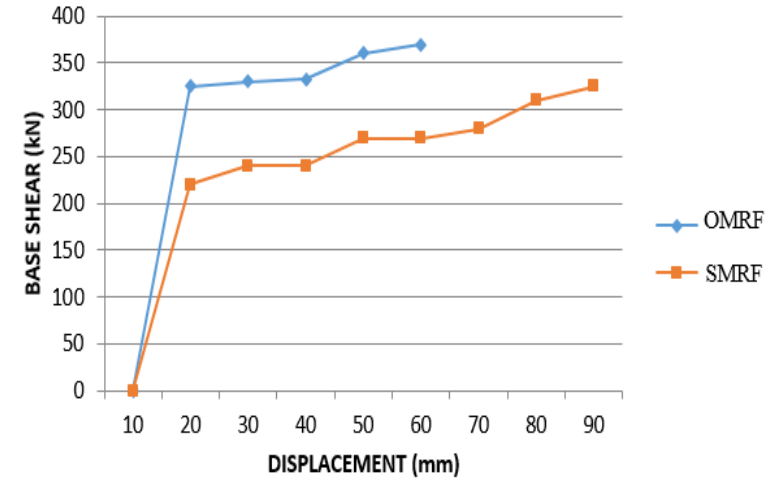

Fig 4.1 Shows The Pushover Curves Of 4S7B OMRF And 4S7B SMRF With Fixed Support Condition And No Infill.

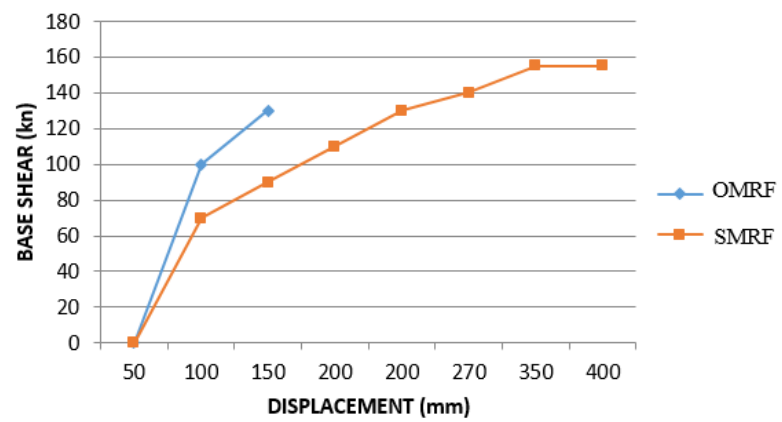

Fig 4.2 Shows The Pushover Curves Of 6S2B OMRF And 6S2B SMRF With Fixed Support Condition And No Infill.

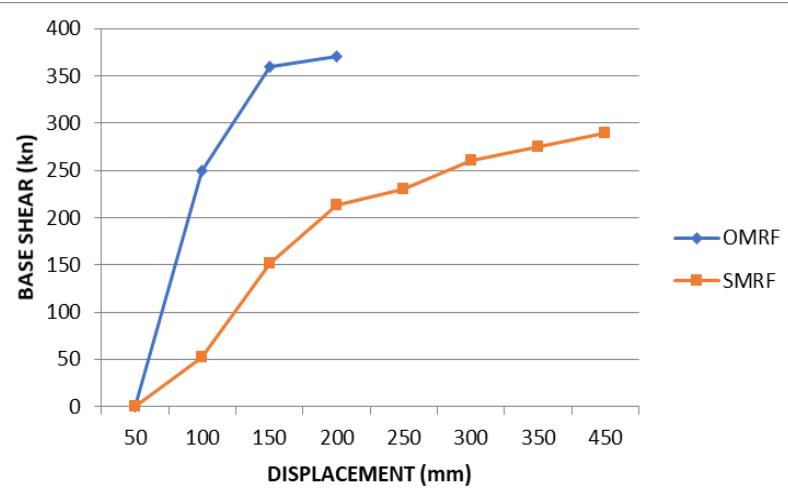

Fig 4.3 Shows The Pushover Curves Of 6S4B OMRF And 6S4B SMRF With Fixed Support Condition And No Infill.

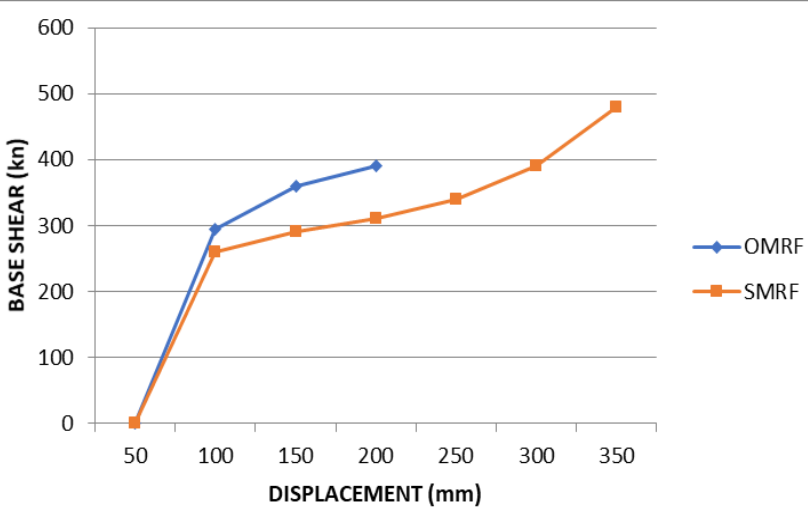

Fig 4.4 Shows The Pushover Curves Of 6S6B OMRF And 6S6B SMRF With Fixed Support Condition And No Infill. 


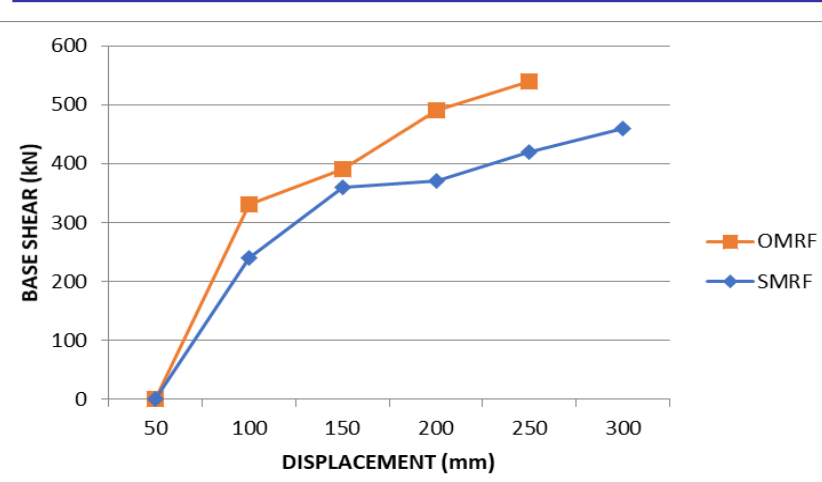

Fig 4.5 Shows The Pushover Curves Of 8S7B OMRF And 8S7B SMRF With Fixed Support Condition And No Infill

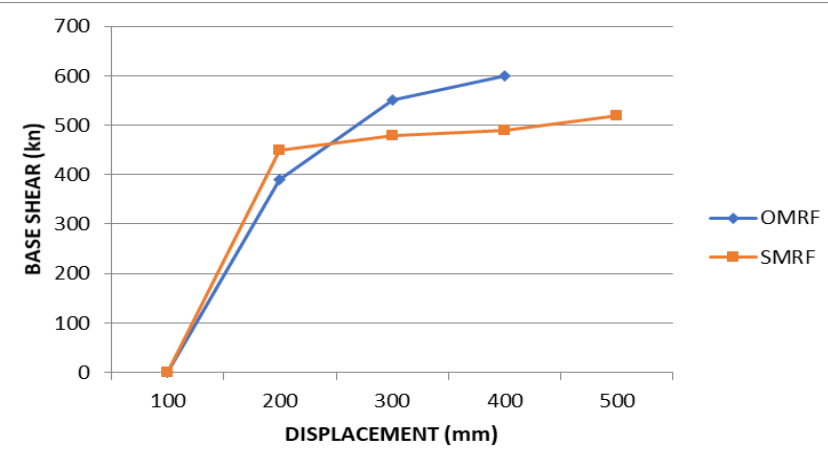

Fig 4.6 Shows The Pushover Curves Of 10S7B OMRF And 10S7B SMRF With Fixed Support Condition And No Infill

\section{B. COMPARISON OF SMRF AND OMRF: BARE FRAME, HINGED SUPPORT}

In this specific comparison, the performance of ordinary moment resisting special moment and frames resisting frames with hinged support situations are deemed. The pushover curves for different configurations of structures are plotted and the construction response is observed.

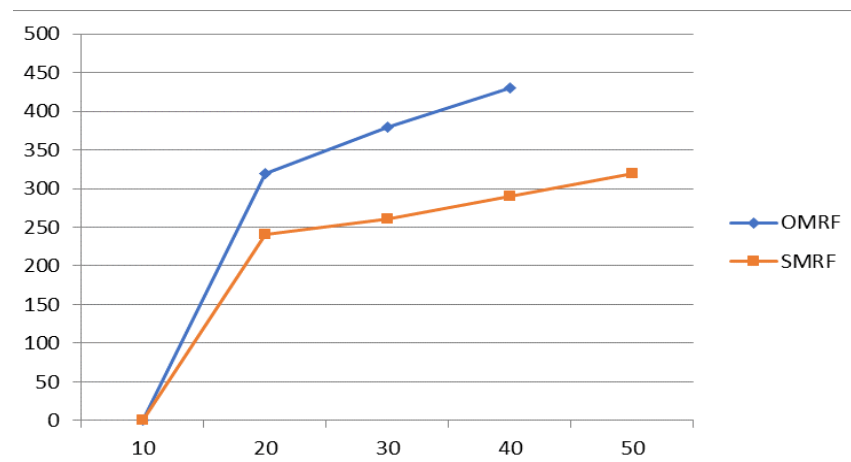

Fig 4.7 Shows The Pushover Curves Of 4S7B OMRF And 4S7B SMRF With

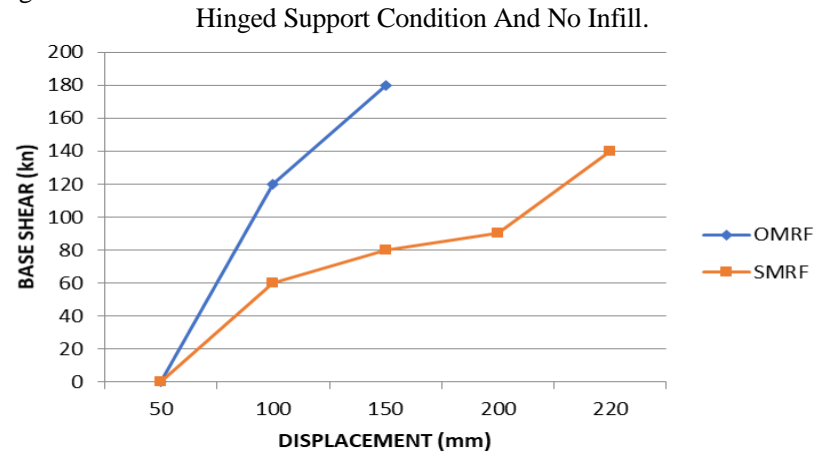

Fig 4.8 Shows The Pushover Curves Of 6S2B OMRF And 6S2B SMRF With Hinged Support Condition And No Infill.

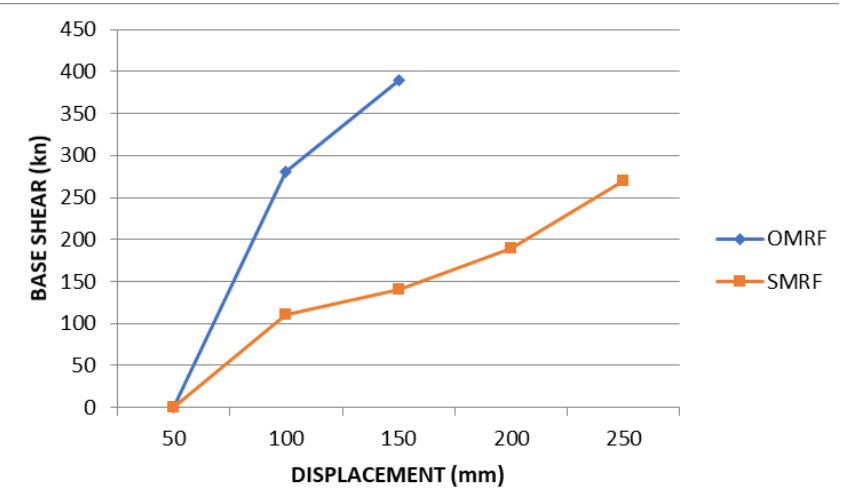

Fig 4.9 Shows The Pushover Curves Of 6S4B OMRF And 6S4B SMRF With Hinged Support condition And No Infill

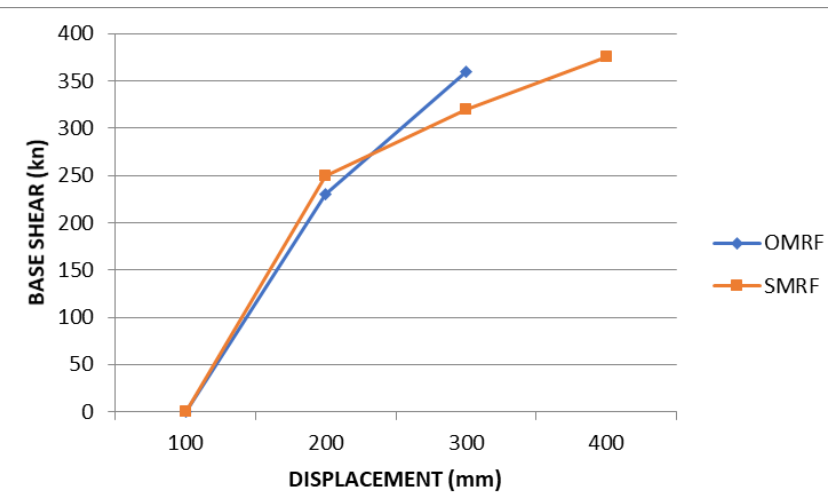

Fig 4.10 Shows The Pushover Curves Of 6S6B OMRF And 6S6B SMRF

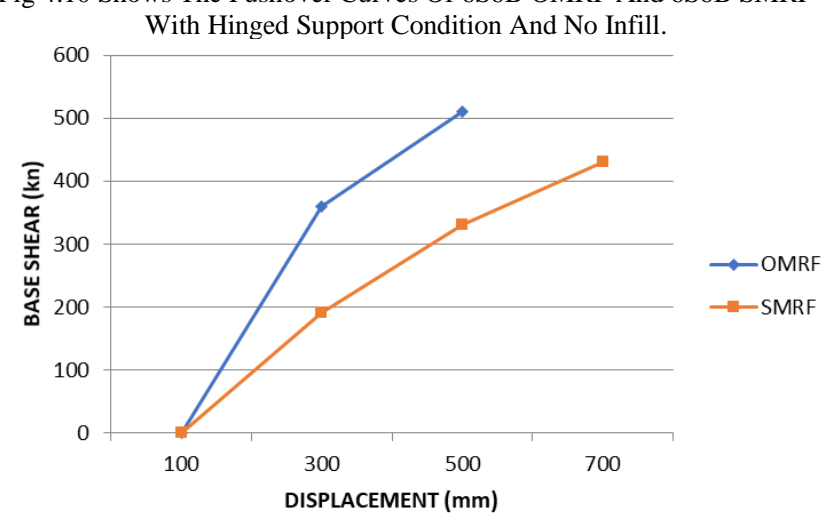

Fig 4.11 Shows The Pushover Curves Of 8S7B OMRF And 8S7B SMRF With Hinged Support Condition And No Infill.

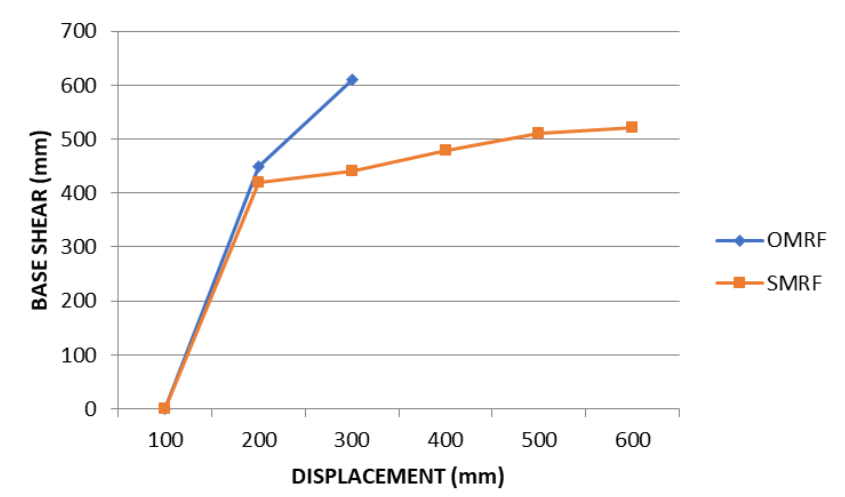

Fig 4.12 Shows The Pushover Curves Of 10S7B OMRF And 10S7B SMRF With Hinged Support Condition And No Infill. 


\section{COMPARISON OF SPECIAL MOMENT RESISTING FRAMES (SMRF) WITH FIXED AND HINGED SUPPORTS.}

The pushover curve of SMRF frames with fixed and hinged support condition is plotted and the outcomes are seen. The pushover curve of 6S4B SMRF-B-F and 6S4B OMRF-B-F is plotted in Fig 4.13.

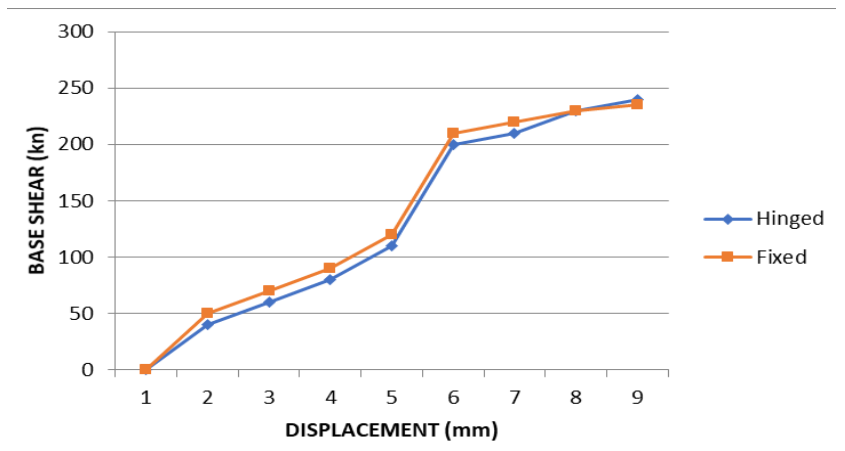

Fig 4.13 Shows The Pushover Curves Of 6S4B SMRF With Both Fixed And Hinged Support Condition And No Infill.

\section{STOREY WISE COMPARISON OF SMRF BUILDINGS}

The buildings with the exact same number of bays are viewed in this specific comparative study. The buildings considered are 4S7B SMRF, 8S7B SMRF And 10S7B SMRF, all having seven bays.

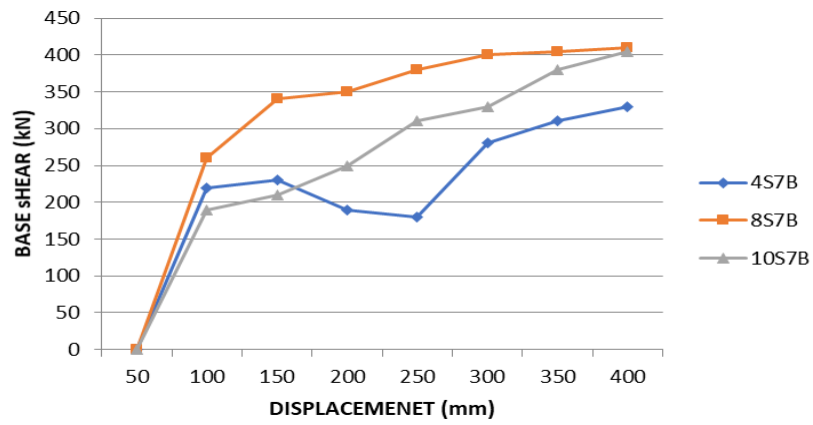

Fig.4.14 Showing The Storey Wise Comparison Of SMRF Buildings With Fixed Support Conditions And No Infill.

\section{E. BAY WISE COMPARISON OF SMRF BUILDINGS}

The buildings with the exact same number of stories are viewed in this specific comparative study. The buildings considered are 6S2B SMRF, 6S4B SMRF And 6S6B SMRF, all having six stories.

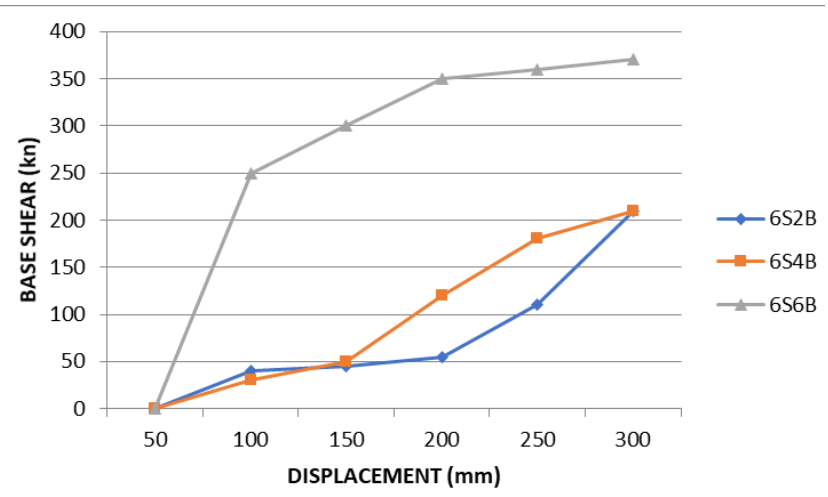

Fig.4.15 Showing The Bay Wise Comparison Of SMRF Buildings With Fixed Support Conditions And No Infill.

\section{F. COMPARISON OF SMRF BUILDINGS WITH STRONG AND} WEAK INFILL: FIXED SUPPORT CONDITION.

In this particular study, the performance of SMRF buildings with weak and strong infill is compared. For strong infill condition the importance of modulus of suppleness of brick is had as $5000 \mathrm{MPa}$ whereas for weak infill it's taken as 350 $\mathrm{MPa}$. In Fig 4.16, the static pushover curve of 6S4B SMRF building with strong and weak infill is shown.

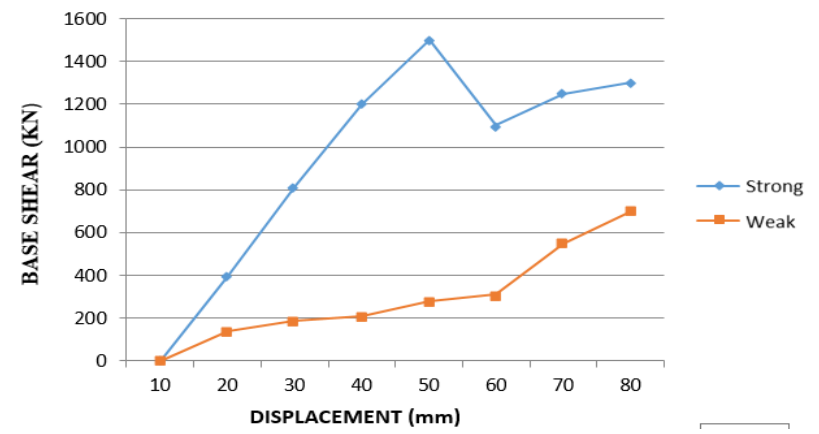

Fig.4.16 Showing The Comparison Of 6S4B SMRF Building With Strong And Weak Infill And Fixed Support Conditions.

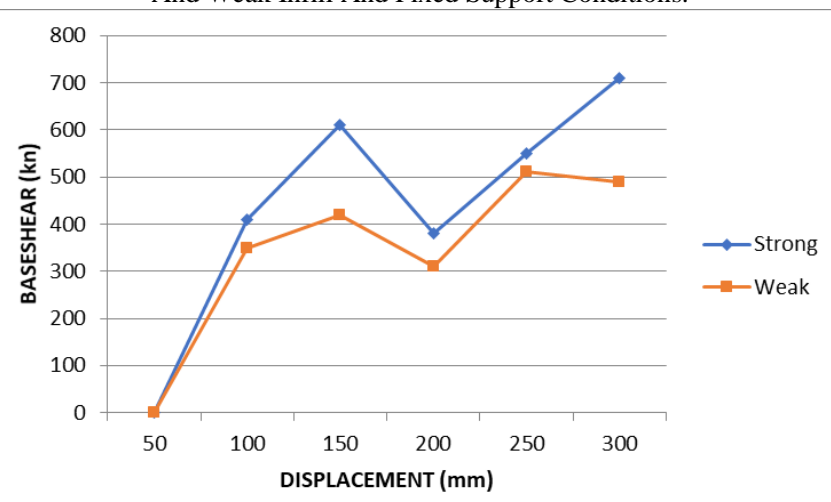

Fig.4.17 Showing The Comparison Of 6S2B SMRF Building With Strong

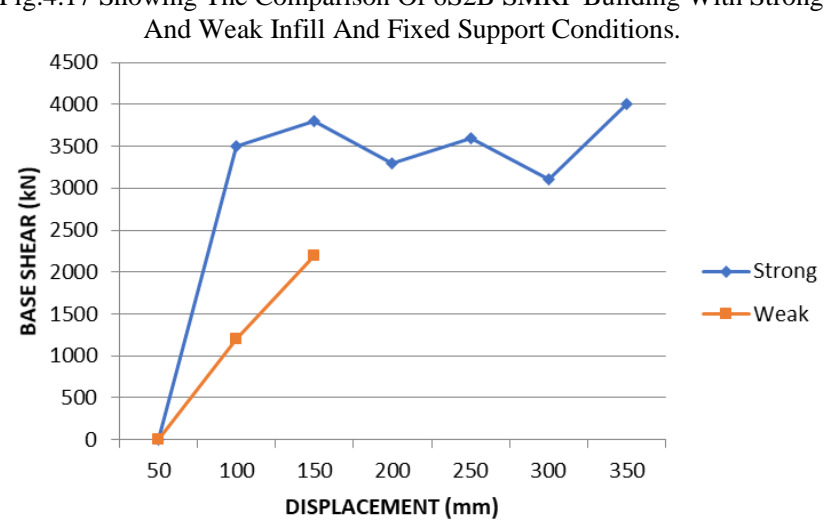

Fig.4.18 Showing the Comparison of 10S7B SMRF Building with Strong and Weak Infill and Fixed Support Conditions.

\section{CONCLUSION}

The efficiency evaluation of buildings designed as Special Moment Resisting Frame (SMRF) and Ordinary Moment Resisting Frame (OMRF) is examined for various building configurations, infill conditions as well as help conditions. The buildings are intended and also modelled utilizing computational software. Several comparative scientific studies are performed to learn the behaviour of OMRF and SMRF:- 
1. The behaviour of SMRF building and also OMRF building without any infill plus fixed support conditions are compared. It's found that the structures designed as SMRF perform much better when compared with the OMRF building. The ductility of SMRF buildings is nearly $75 \%-200 \%$ more than the OMRF structures in all of instances, why simply being the large confinement of concrete on account of usage and splicing of even more number of stirrups as ductile reinforcement. It's likewise discovered that the base shear electrical capacity of OMRF buildings is 20 to $40 \%$ much more than that of SMRF buildings.

2. The behaviour of SMRF building and also OMRF building without any infill and also hinged support conditions are compared. It's discovered that the structures designed as SMRF perform far better when compared with the OMRF building. The ductility of SMRF is much more in most instances and that has gone approximately 75-200 \% than that of OMRF buildings. But OMRF buildings resist 20-40 \% additional base shear than that be opposed by SMRF buildings

3. The SMRF buildings with exact same number of different number and bays of stories are compared. The pushover curve is plotted and also it's discovered that the magnitude and the ductility of base shear which may be resisted, increases with rise in the quantity of stories. It's found that all of the SMRF buildings considered has practically similar value of first slope in the thrust over curve.

4. The SMRF buildings with exact same amount of different number and stories of bays are compared. The pushover curve is plotted and also it's found that the magnitude of base shear which may be resisted increases with rise in the number of bays. As the number of bays increases from two to four, the base shear capacity increases by two times. When it improves from two bays to six bays, the magnitude of the base shear the structure is able to withstand increase by three times it may be suggested that the number of bays have a significant part in the stability of the buildings considered for the current study.

5. The SMRF buildings with weak and strong infill are compared and also it's discovered that the structures with strong infill is able to tolerate a better magnitude of base shear when than all those with weak infill. It may be realized that the SMRF buildings with much stronger infill have base shear capacity of approximately 1.5 to
2.5 times over that of SMRF buildings with weak infill. Although, a highly accurate conclusion can't be pulled away for ductility, it could be recommended that weak infill isn't better due to the linear nature of theirs within the pushover curve.

\section{REFERENCES}

[1] Rao Pradip, Sarkar. (Dec. 2008),"Seismic Evaluation of Reinforced concrete stepped building frames", A thesis for the award of the degree of doctor of philosophy, IIT Madras, Chennai.

[2] Rutenberg, A., (1992),'Nonlinear Response of Asymmetric Building Structures and Seismic Codes: A State of the Art Review", European Earthquake Engineering,6(2), 3-19.

[3] Riddington, J. R. and S. B. Smith (1997) Analysis of infilled frames subject to racking with design recommendations. The Structural Engineer. 55. 263-268

[4] Krawinkler, H., \& Seneviratna, G. D. P. K. (1998),'Pros and cons of a pushover analysis of seismic performance evaluation", Engineering Structures, 20(4- 6), 452-464.

[5] Hasan, R., Xu, L., \& Grierson, D. E. (2002)," Push-over analysis for performance based seismic design", 80(July), 2483-2493.

[6] Akbas, B., Kara, F.I., and Tugsal, U.M. (2003), "Comparison of Pushover Analysis and Nonlinear Dynamic Time History Analysis on Low-, Medium-, and High-Rise Steel Frames", Project No. 02-A-0201-03, Scientific Research Project Fund, Gebze Institute of Technology

[7] Murty,Das C. V. R.(2002),'Performance of reinforced concrete frame buildings during 2001 Bhuj earthquake",Proceedings of the 7th US National Conference on Earthquake Engineering. Boston. USA. Paper No. 745

[8] Sermin Oguz. (2005),"A thesis on "Evaluation of Pushover Analysis Procedures for Frame Structures", April, 2005.

[9] X.-K. Zou, C.-M. Chan.(2005),'Optimal seismic performance-based design of reinforced concrete buildings using nonlinear pushover analysis",Department of Civil Engineering, Hong Kong University of Science and Technology, Kowloon, Hong Kong, China

[10] Asokan, A., (2006) Modelling of Masonry Infill Walls for Nonlinear Static Analysis of Buildings under Seismic Loads. M. S. Thesis, Indian Institute of Technology Madras, Chennai

[11] IS: 13920, (2002)," Indian Standard Code of Practice for Ductile Detailing of Reinforced Concrete Structure Subjected to Seismic Forces", Bureau of Indian Standards, New Delhi.

[12] IS 1893 Part 1, (2002),"Indian Standard Criteria for Earthquake Resistant Design of Structures", Bureau of Indian Standards, New Delhi.

[13] IS: 456 (Fourth Revision), (2000),'Indian standard code for practice for plain reinforced concrete for general building construction", Bureau of Indian Standards, New Delhi.

[14] IS 875Part 1, 2, 3 and 4, (1987),"Indian Standard Code of practice for Design loads for buildings and structures",Bureau of Indian Standards, New Delhi. 